Article

\title{
Improving ICT and renewable energy for environmental sustainability in sub-Saharan Africa
}

\author{
Ibrahim Kabiru Maji ${ }^{1^{*}}$ and Salisu Ibrahim Waziri ${ }^{2}$ \\ 1 Department of Economics, Faculty of Social and Management Sciences, Bauchi State University, Gadau, \\ Nigeria; keibimaji@gmail.com \\ 2 Department of Economics, Faculty of Social and Management Sciences, Bauchi State University, Gadau, \\ Nigeria; ciwaziri@gmail.com \\ * Correspondence: keibimaji@gmail.com
}

Received: 6 February 2020; Accepted: 7 June 2020; Published: 10 June 2002

\begin{abstract}
The study investigates the role of information and communication technology (ICT) and renewable energy on environmental sustainability in sub-Saharan Africa. The system generalized method of moments (GMM) was employed to estimate data of 45 sub-Saharan countries that cover the 2008 -2016 period. Result reveals that increasing ICT penetration and renewable energy use reduce $\mathrm{CO}_{2}$ emissions and improves environmental sustainability. Economic growth and population growth also mitigate $\mathrm{CO}_{2}$ emissions while education and trade openness have a neutral impact. These findings imply that increasing penetration of ICT facilities and renewable energy in the region will promote inclusive environmental sustainability. The interactive estimation of ICT variables was further considered to determine net effects and the ICT threshold that is relevant for policy implication.
\end{abstract}

Keywords: ICT; renewable energy; sustainable environment; sub-Saharan Africa

JEL codes: L63; Q20; Q56

\section{Introduction}

Information and Communication Technology (ICT) plays an important role in this era of globalization and economic integration. It has assisted in reducing information costs and information asymmetry. ICT has enhanced energy efficiency, financial development, and economic growth processes (Pradhan et al., 2015; World Bank, 2016). Also, ICT has provided a platform for collaboration between business partners; reduces geographical barriers, and facilitates innovation. The International Energy Agency (IEA) in 2017 observed that more than 3.5 billion people, which is about half of the world population are now using the internet while mobile communication subscriptions have increased by more than three-time, exceeding 4 billion active subscriptions.

However, the increasing benefit of ICT cannot be without an opportunity cost. The proliferation of ICT infrastructure may have important environmental consequences (Salahuddin and Alam, 2016), such as increasing the use of non-renewable energy that increase the presence of greenhouse gases from Carbon dioxide $\left(\mathrm{CO}_{2}\right)$ emissions. Relating ICT to environmental performance is relatively a new area of inquiry, as such, there is no agreement in the literature on its precise impact on the environment. ICT can mitigate $\mathrm{CO}_{2}$ emissions when cleaner energy sources like solar, wind and hydropower are used to power ICT facilities like the internet and mobile phones. On the contrary, the use of unclean energy sources from fossil fuels to power ICT gadgets may increase environmental pollutions.

This study is motivated by the following reasons: the concern about environmental pollution that might arise from the inefficient use of ICT facilities in sub-Saharan Africa; the potential of ICT 
penetration in the region; the role renewable energy consumption can play in improving environmental sustainability and reducing greenhouse gas arising from $\mathrm{CO}_{2}$ emissions; the fact that investigating ICT and environmental sustainability is a new and ongoing debate and; the gap in the extant literature of not including renewable energy variable.

The increase in greenhouse gas in the last ten decades has been attributed to $\mathrm{CO}_{2}$ emissions as the main gas leading to global warming and climate change (World Bank, 2016). In the same vein, studies have observed that $\mathrm{CO}_{2}$ emission is at the center stage of the greenhouse gas responsible for environmental pollution in African sub-regions (e.g. Mehdi and Slim, 2017). However, information technologies can support energy systems around the African region to be more efficient, reliable, and sustainable. Unfortunately, ICT as an instrument for managing the environment has been ignored as an important aspect of environmental governance (Asongu et al., 2017).

Correspondingly, the sub-Saharan African region is endowed with huge renewable energy resource potentials such as solar, wind, biomass, hydropower, and geothermal that is enough to meet the energy need of its people and reduce environmental pollution. However, energy resources and technologies are underdeveloped (IEA, 2017). A large population of the region's people relies on the inefficient use of biomass for heating and cooking and the use of a generator for energy. Moreover, to effectively reap the benefit of renewable energy as a tool for mitigating environmental problems in the region, the role of ICT cannot be ignored.

This paper examines the impact of ICT and renewable energy on reducing greenhouse gas from $\mathrm{CO}_{2}$ emissions. The contribution of this study is as follows. The study deviates from recent literature on ICT, economic and growth and $\mathrm{CO}_{2}$ emissions (Pradhan et al., 2015; Erumban and Das, 2016; Salahuddin and Alam, 2016) and sub-Saharan African studies (Asongu et al., 2017a; Asongu et al., 2017b; Haftu, 2018), by including renewable energy consumption in the nexus between ICT and environmental sustainability. To the best of our knowledge, this is the first-time renewable energy variable is included in this framework. Including renewable energy in the ICT - environmentally sustainable nexus can help to explain the extent to which ICT and renewable energy can be used as an important environmental policy measure. Additionally, the study is a bit different from other studies in terms of the data set, sample period, and variable measurement. More, so, this study employed a system generalized method of moments which is a more robust estimator compared to pooled, fixed, and random regression techniques. To avoid model specification bias, more conditional variables were included in the study.

\section{Literature Review}

Several studies have investigated the relationship between ICT, economic growth and other important variables like financial development, electricity consumption, education, energy consumption, downsizing, energy security and social capital (Pradhan et al., 2015; Jorgenson et al., 2016; Erumban and Das, 2016; Pfeifer et al., 2018; Céspedes-Lorente et al., 2018; Ribeiro et al., 2018; Abu and Bressler, 2018; Pradhan et al., 2018; Hache, 2018; Yang et al., 2018; Thompson, 2018; Benighaus, 2019; Lin and Chen, 2019). These pieces of literature have arrived at inconclusive results largely due to differences in variable measurements, sample sizes, methodologies, countries of study, and level of development.

Some of the studies established a positive and important link between ICT and economic growth; some suggest an indirect relationship between ICT and economic growth while others observed a neutral outcome between ICT and economic growth. For instance, Pradhan et al. $(2015,2018)$ hinted that the enhancement of ICT infrastructure in a country's information technology (IT) policy formulation for broadband and internet users, increases economic growth. On the contrary, Jorgenson et al. (2016) found that a slight portion of the fall in the growth rate in the United States during the great recession is associated with information technology-producing industries. However, these studies have not included an environmental indicator such as $\mathrm{CO}_{2}$ emissions and renewable energy consumption in their inquiry. 
In sub-Saharan Africa, ICT and the economic growth nexus have recently been examined (Haftu, 2018; Donou-Adonsou, 2018). Haftu (2018) evaluated the influence of mobile phones and the internet on the economic growth of Sub-Saharan Africa using the system generalized method of moments for a sample of 40 countries. The findings reveal that progression in mobile phone penetration has significantly contributed to economic growth in the region. Similarly, Donou-Adonsou (2018) explores the role of ICT infrastructure on economic growth in the presence of educational quality and it's otherwise in sub-Saharan Africa. The result shows that the internet contributes to economic growth in countries with better access to education while mobile phone has a neutral effect. These studies did not also include renewable energy and environmental indicator in their analysis.

The work of Asongu et al. (2017a) and Asongu et al. (2017b) for sub-Saharan Africa which examines the effect of enhancing ICT facilities such as internet and mobile phone penetration on environmental sustainability are closely related to this study. The former found that ICT infrastructure has a net positive impact on $\mathrm{CO}_{2}$ emissions but increasing mobile phone penetration has a negative net impact on $\mathrm{CO}_{2}$ emissions from liquid fuel consumption. The later observed that ICT can be used to reduce the possible negative impact of the environment on human development. Despite the closeness of this literature to our inquiry, they did not include renewable energy in the ICTenvironmental sustainability nexus, and thus, constitutes a literature gap.

This study examines the impact of ICT and renewable energy on environmental sustainability in sub-Saharan Africa. Including renewable energy in the ICT - $\mathrm{CO}_{2}$ emissions nexus has so far not been found in the engaged literature. However, its inclusion can assist in explaining the extent to which ICT can serve as a useful environmental policy tool.

\section{Data and Methods}

\subsection{Model estimation}

The modeling strategy of this study follows closely to the work of Asongu et al. (2017a), Asongu et al. (2017b), and Bhattacharya et al. (2017). However, the study augments their $\mathrm{CO}_{2}$ emission's model by including renewable energy as an additional hypothesized variable. We have also included the conditional variable of GDP per capita to account for the macro-economy, trade openness to account for globalization, population growth to account for the market, and education quality to account for literacy level.

The estimation method for this study is the system generalized method of moments (GMM). The reasons for using this estimator are: The study has large cross-section data and small-time period, i.e. the sample size of countries (45) is greater than the number of years (9); the estimator controls for endogeneity and reverse causality by using instruments and time-invariant omitted variables; bias in the difference estimator of Arellano and Bond (1991) can be corrected by the system GMM technique by encompassing level information (see Arellano and Bover, 1995; Blundell and Bond, 1998). The Arellano and Bover (1995) further extended by Roodman (2009) reduces the proliferation of instrument and account for cross-section dependence (Baltagi, 2008; Bhattacharya et al., 2017; Asongu et al., 2017a).

Thus, the following equations 1 and 2 summarizes the standard system GMM model in the level and first difference forms while equation 3 is the two-way error term component.

$$
\begin{aligned}
& \mathrm{CO}_{2, i, t}=\sigma_{o}+\sigma_{1} \mathrm{CO}_{2, i, t-1}+\sigma_{2} I C T_{i, t}+\sigma_{3} R E N_{i, t}+\sum_{p=1}^{2} \sigma_{4} W_{i, t-1}+\mu_{i, t} \\
& \mathrm{CO}_{2, i, t}-\mathrm{CO}_{2, i, t-1}=\sigma_{1}\left(\mathrm{CO}_{2, i, t-1}-\mathrm{CO}_{2, i, t-2}\right)+\sigma_{2}\left(I C T_{i, t}-I C T_{i, t-1}\right)+\sigma_{3}\left(\operatorname{REN}_{i, t}-R E N_{i, t-1}\right)+ \\
& \sum_{p=1}^{2} \sigma_{4}\left(W_{i, t-1}-W_{i, t-2}\right)+\left(\mu_{i, t}-\mu_{i, t-1}\right) \\
& \mu_{i, t}=\rho_{i}+\theta_{t}+\vartheta_{i, t}
\end{aligned}
$$

where $\boldsymbol{C O}_{2}$ representing $\mathrm{CO}_{2}$ emissions from liquid fuel consumption of country $\boldsymbol{i}$ at period $\boldsymbol{t} ; \boldsymbol{\sigma}_{\boldsymbol{o}}$ is the constant term, ICT represent information and communication technology, REN denotes renewable energy, $\boldsymbol{W}$ represent the vector of conditional variables (GDP per capita, trade openness, population growth and education). $\boldsymbol{\mu}_{\boldsymbol{i}, t}$ is the two-way stochastic error term, $\boldsymbol{\rho}_{\boldsymbol{i}}$ is the country- 
specific effect, $\boldsymbol{\theta}_{\boldsymbol{t}}$ is the time-specific effect while $\boldsymbol{\vartheta}_{\boldsymbol{i}, \boldsymbol{t}}$ is the error term. We expect a negative relationship between the outcome variable $\mathrm{CO}_{2}$ emissions and the two hypothesized variables ICT, renewable energy and one control variable - education. A positive relationship is also expected between $\mathrm{CO}_{2}$ emissions and the conditional variables of GDP per capita, trade openness, and population growth.

In addition to the modeling strategy, identification restriction is important to achieving a good GMM specification. In line with recent studies (Asongu and Acha-anyi, 2019), all hypothesized variables are suspected to be endogenous, while only time-invariant measurements are used as strictly exogenous. This identification approach is in line with Asongu and Odhiambo (2019) who maintained that time-invariant measurements are mostly not endogenous after their first difference. With regards to the exclusion restriction, the outcome variable is affected by the time-invariant through the suspected endogenous variable. Hoverer, this can be overcome when the null hypothesis for instrument exogeneity is accepted (Tchamyou et al. (2019).

\subsection{Data}

The data for this study are sourced from World Development Indicators (WDI) and African Development Indicators (ADI) for 2008 - 2016 period. Also, 45 sub-Saharan African countries constitute the sample size. The choice of data period and the sample size are detected by data availability. $\mathrm{CO}_{2}$ emission is measured by $\mathrm{CO}_{2}$ emissions from liquid fuel consumption (\% of total). ICT is measured by Mobile cellular subscriptions (per 100 people) and internet users (per 100 people). Renewable energy is measured by renewable energy consumption ( $\%$ of total final energy consumption). Economic growth is measured by GDP per capita (constant 2010 US\$). Trade openness is measured by Trade (\% of GDP). Population growth is proxy by population growth (annual \%) while education quality is measured by the pupil-teacher ratio in primary school. The list of countries included in the sample size is presented in Table $1 \mathrm{a}$.

Table 1a. List of countries in the panel

\begin{tabular}{ccc}
\hline Angola & Eritrea & Mozambique \\
Benin & Ethiopia & Namibia \\
Botswana & Gabon & Niger \\
Burkina Faso & The Gambia & Nigeria \\
Burundi & Ghana & Rwanda \\
Cabo Verde & Guinea & Sao Tome and Principe \\
Cameroon & Guinea-Bissau & Senegal \\
The central African Republic & Kenya & Seychelles \\
Chad & Lesotho & Sierra Leone \\
Comoros & Liberia & South Africa \\
Dem. Rep. of Congo & Madagascar & Tanzania \\
Congo, Rep. & Malawi & Togo \\
Cote d'Ivoire & Mali & Uganda \\
Djibouti & Mauritania & Zambia \\
Equatorial Guinea & Mauritius & Zimbabwe \\
\hline
\end{tabular}

Table $1 \mathrm{~b}$. presents the descriptive statistics and the correlation matrix of variables. The descriptive statistics include the mean standard deviation, minimum and maximum values. The description shows that the average value of GDP per capita is the highest followed by trade openness and $\mathrm{CO}_{2}$ emissions from liquid fuel consumption while population growth has the least average value in the observation. More, so, internet usage is the most volatile observation given its standard deviation 
while education quality observation has the least standard deviation hence the least volatile observation. Like the average value, the GDP per capita has the value with the maximum observation while population growth has the minimum value. The correlation analysis is also presented below the descriptive statistics in Table $1 \mathrm{~b}$. The result suggests that the variables are not highly correlated because the correlation coefficients are less than 0.80 , which is the rule of thumb for variables to be correlated. As such, the results are free from the multicollinearity problem.

Table 1b. Descriptive statistics and correlations of variables

\begin{tabular}{|c|c|c|c|c|c|c|c|c|}
\hline & $\mathrm{CO}_{2} \mathrm{LFC}$ & Mobile & Internet & REN & $G D P P C$ & TRDO & POPG & $E D U C$ \\
\hline Mean & 4.229 & 3.937 & 1.861 & 3.962 & 7.059 & 4.295 & 0.843 & 3.659 \\
\hline Standard Dev. & 0.498 & 0.725 & 1.145 & 0.866 & 1.088 & 0.401 & 0.540 & 0.362 \\
\hline Minimum & 2.296 & 0.854 & -1.386 & -0.959 & 5.386 & 3.031 & -2.678 & 2.529 \\
\hline Maximum & 4.605 & 5.089 & 4.035 & 4.575 & 9.920 & 5.416 & 1.527 & 4.608 \\
\hline Cross-sections & 45 & 45 & 45 & 45 & 45 & 45 & 45 & 45 \\
\hline \multicolumn{9}{|c|}{ Correlation coefficients } \\
\hline Mobile & -0.317 & & & & & & & \\
\hline Internet & -0.371 & 0.758 & & & & & & \\
\hline REN & 0.428 & -0.496 & -0.556 & & & & & \\
\hline$G D P P C$ & -0.239 & 0.479 & 0.556 & -0.495 & & & & \\
\hline TRDO & -0.044 & 0.376 & 0.192 & -0.281 & 0.419 & & & \\
\hline$P O P G$ & 0.011 & -0.249 & -0.365 & 0.301 & -0.089 & -0.064 & & \\
\hline EDUC & 0.258 & -0.335 & -0.311 & 0.306 & -0.315 & -0.175 & 0.099 & \\
\hline
\end{tabular}

Notations $\mathrm{CO}_{2} L F C$, Mobile, Internet, REN, GDPPC, TRDO, POPG, and EDUC stand for $\mathrm{CO}_{2}$ emissions from liquid fuel consumption, mobile phone subscription, internet usage, renewable energy, GDP per capita, trade openness, population growth, and education quality respectively.

\section{Results and Discussion}

Table 2 presents the empirical results of the impact of ICT and renewable energy on $\mathrm{CO}_{2}$ emissions in sub-Saharan Africa. The coefficients of lagged dependent variables $\mathrm{CO}_{2}$ emissions from liquid fuel consumption for the ICT models are all significant, indicating that the models are dynamic. The (AR2) null hypotheses for Arellano and Bond (1991) for the absence of autocorrelation in the stochastic error term were accepted. The Hansen test and difference in Hansen test null hypotheses for overidentification restriction and exogeneity of instruments are respectively not rejected (Asongu et al (2017a). The large cross-section data along with a small-time period have further justified the use of system GMM in this study.

For the non-interactive estimation of the role of ICT and renewable energy on environmental sustainability, two models were estimated. One for the mobile phone and the other for the internet as presented in columns two and four of Table 2. The first model for mobile phones reveals a negative relationship between ICT indicator and $\mathrm{CO}_{2}$ emissions indicating that increasing ICT will mitigate $\mathrm{CO}_{2}$ emissions and thus, improves environmental sustainability. In the same model, the relationship between renewable energy and $\mathrm{CO}_{2}$ emissions is negative and also significant suggesting that increasing the use of renewable energy in sub-Saharan Africa will increase environmental sustainability via $\mathrm{CO}_{2}$ emissions reduction. Also, the result of the control variables suggests that economic growth, population growth, and education quality can also mitigate $\mathrm{CO}_{2}$ emissions. However, the effect of trade openness is neutral.

Similarly, the second model of internet subscription presented in Table 2 reveals that ICT and renewable energy have a favorable impact on environmental sustainability. This is supported by the negative and significant signs of ICT and renewable energy coefficients. The control variables for economic growth and population growth also revealed a favorable impact on environmental sustainability while trade openness and education quality are neutral. The implication of these results is: (i) increasing penetration of ICT facilities such as the mobile phone subscriptions and internet users 
in sub-Saharan African is an inclusive strategy for environmental sustainability. (ii) Increasing the renewable energy mix of the region by harnessing the potential of available solar, wind, hydropower, biomass, and geothermal will reduce over-reliance on traditional energy and thus, improve environmental sustainability. (iii) Economic growth and quality of population are important for the region's environmental sustainability. However, trade and level of education need to be further enhanced to achieve efficient environmental quality.

Table 2. Impact of ICT and renewable energy on $\mathrm{CO}_{2}$ emissions

\begin{tabular}{|c|c|c|c|c|}
\hline & \multicolumn{4}{|c|}{ System GMM } \\
\hline & \multicolumn{4}{|c|}{ Dependent variable $=\mathrm{CO}_{2}$ emissions from liquid fuel consumption } \\
\hline & \multicolumn{2}{|c|}{ Mobile phone } & \multicolumn{2}{|c|}{ Internet } \\
\hline \multirow{2}{*}{$C \mathrm{O}_{2} L F C_{t-1}$} & $0.763^{* * *}$ & $0.634^{* * *}$ & $0.728^{* * *}$ & $0.822^{* * *}$ \\
\hline & $(0.049)$ & $(0.106)$ & $(0.042)$ & $(0.028)$ \\
\hline \multirow[t]{2}{*}{ Mobile } & $-0.027^{* * *}$ & $-0.195^{*}$ & - & - \\
\hline & $(0.009)$ & $(0.106)$ & & \\
\hline \multirow[t]{2}{*}{ Internet } & - & - & $-0.017^{* * *}$ & 0.008 \\
\hline & & & $(0.007)$ & $(0.014)$ \\
\hline \multirow[t]{2}{*}{ Mobile $*$ Mobile } & - & $0.025^{*}$ & - & - \\
\hline & & $(0.014)$ & & \\
\hline \multirow[t]{2}{*}{ Internt $*$ Internet } & - & - & - & $-0.009^{* *}$ \\
\hline & & & & $(0.005)$ \\
\hline \multirow[t]{2}{*}{$R E N$} & $-0.081^{* * *}$ & $-0.116^{* *}$ & $-0.099^{* * *}$ & $-0.059^{* * *}$ \\
\hline & $(0.018)$ & $(0.061)$ & $(0.036)$ & $(0.018)$ \\
\hline \multirow[t]{2}{*}{$G D P P C$} & $-0.124^{* *}$ & -0.126 & $-0.197^{* * *}$ & $-0.144^{* * *}$ \\
\hline & $(0.053)$ & $(0.081)$ & $(0.046)$ & $(0.021)$ \\
\hline \multirow[t]{2}{*}{$T R D O$} & 0.038 & 0.065 & 0.017 & $0.052^{*}$ \\
\hline & $(0.028)$ & $(0.091)$ & $(0.036)$ & $(0.031)$ \\
\hline \multirow[t]{2}{*}{$P O P G$} & $-0.072^{* * *}$ & $-0.107^{* *}$ & $-0.123^{* * *}$ & $-0.172^{* * *}$ \\
\hline & $(0.012)$ & $(0.046)$ & $(0.029)$ & $(0.031)$ \\
\hline \multirow[t]{2}{*}{$E D U C$} & $-0.061^{* * *}$ & 0.090 & -0.163 & $-0.225^{* * *}$ \\
\hline & $(0.122)$ & $(0.712)$ & $(0.109)$ & $(0.074)$ \\
\hline \multirow[t]{2}{*}{ Constant } & $2.413^{* * *}$ & 2.730 & $3.574^{* * *}$ & $2.775^{* * *}$ \\
\hline & $(0.918)$ & $(1.348)$ & $(0.785)$ & $(0.560)$ \\
\hline Net effects & - & -0.0966 & - & -0.00875 \\
\hline $\mathrm{AR}(2)$ & 0.398 & 0.539 & 0.378 & 0.304 \\
\hline Hansen P-value & 0753 & 0.579 & 0.456 & 0.194 \\
\hline Dif. Hansen P-value & 0629 & 0.210 & 0.490 & 0.057 \\
\hline Number of & 29 & 25 & 29 & 33 \\
\hline \multicolumn{5}{|l|}{ Instruments } \\
\hline Cross-sections & 43 & 43 & 43 & 43 \\
\hline No of observation & 191 & 191 & 190 & 190 \\
\hline
\end{tabular}

Note: ${ }^{* *} \mathrm{p}<0.05$ and ${ }^{* * *} \mathrm{p}<0.01$ indicates significance at $5 \%$ and $1 \%$ respectively. Values in parenthesis are standard errors. Notations $\mathrm{CO}_{2} L F C$, Mobile, Internet, REN, GDPPC, TRDO, POPG and EDUC stand for $\mathrm{CO}_{2}$ emissions from liquid fuel consumption, mobile phone subscription, internet usage, renewable energy, GDP per capita, trade openness, population growth and education quality respectively. AR (2) is the second-order autocorrelation test while Hansen p-value and Dif. Hansen is test for over-identification restrictions and erogeneity of instrument respectively.

Moreover, net effects are estimated to ascertain the overall impact of increasing ICT on environmental sustainability. In column three of Table 2 , the net effect from improving mobile phone penetration is estimated to be $-0.0966([0.025 \times 3.937]+[-0.195])$. This was arrived at by multiplying the mean value of mobile phones by the marginal effect from its increase and then adding the unconditional effect of mobile penetration. Following a similar procedure, the net effect of improving 
internet penetration is estimated from column five of Table 2 to be -0.00875 . These computations of net effects are consistent with the recent work in this area (Asongu et al., 2017; Boateng et al., 2018).

The results of the interactive estimations suggest that increasing ICT (mobile phone and internet penetration) have a negative net effect on $\mathrm{CO}_{2}$ emissions. These negative marginal effects imply that ICT needs to be penetrated to a certain threshold before it can enhance environmental sustainability. For the thresholds to have policy relevance, they must be within the range of minimum and maximum values of summary statistics of the data (Boateng et al., 2018).

The threshold for mobile phone penetration is $7.8(0.195 / 0.025)$ while that of internet penetration is $0.889(0.008 / 0.009)$. Since the threshold of mobile phone is 7.8 , only the estimated threshold of internet penetration makes economic sense for policy relevance, because 0.889 falls within the range of (-1.386 and 4.035). Thus, increasing the internet penetration rate beyond 0.889 per 100 people will dampen $\mathrm{CO}_{2}$ emissions and improve environmental sustainability.

\section{Conclusions}

The study explores the role of ICT and renewable energy on environmental sustainability using $\mathrm{CO}_{2}$ emissions from liquid fuel consumption as a measure of carbon emissions. The system generalized method of moments (GMM) was utilized as the empirical technique while a sample of 45 sub-Saharan countries covering the $2008-2016$ period was used. For the non-interactive regressions, the result shows that all the ICT variables have a negative relationship with $\mathrm{CO}_{2}$ emissions signifying that an increase in ICT will reduce $\mathrm{CO}_{2}$ emissions and subsequently improves environmental sustainability. Furthermore, the result reveals that renewable energy has a negative relationship with $\mathrm{CO}_{2}$ emissions suggesting that increasing the use of renewable energy will improve environmental sustainability. The result of the conditional variables shows that economic growth and population growth also mitigate $\mathrm{CO}_{2}$ emissions while education and trade openness have a neutral impact.

These results imply that increasing ICT penetration such as enhanced mobile phone subscriptions and efficient internet users in sub-Saharan African will be a good policy instrument of improving environmental sustainability in the region. Thus, policies and incentives that encourage the use of ICT facilities should be further promoted. Furthermore, increasing the renewable energy mix of the region through exploiting the potential of available renewable energy will reduce over-reliance on conventional energy and thus, improve environmental sustainability. Therefore, policies that would encourage private sector participation in renewable energy usage should be further promoted.

For the estimated result to fully reflect the objective of this inquiry and corresponding implications, net effects where computed from the interactive estimation of ICT variables. Based on the interactive estimations, we concluded that increasing ICT has a net negative effect on $\mathrm{CO}_{2}$ emissions, which suggests that ICT penetration will improve environmental sustainability. These marginal effects imply that ICT penetration needs to be further strengthened to a certain threshold to achieve the desired effect of mitigating $\mathrm{CO}_{2}$ emissions. In the computation of the threshold, only the result of internet penetration is within the practical range and thus, has practical policy implication. Therefore, the internet penetration rate beyond 0.889 for every100 people will mitigate $\mathrm{CO}_{2}$ emissions and improves environmental sustainability.

The main policy implication of these findings is that internet penetration can be used as an instrument for mitigating $\mathrm{CO}_{2}$ emissions in sub-Saharan African. The threshold at which this is possible makes economic meaning for internet usage since the internet can be used on many devices including the mobile phone (Asungu et al. 2017). More, so, policymakers can take advantage of these findings to address the problems militating against internet penetration such as providing internet infrastructure and breaking the monopoly of the internet providers to pave way for competition that will further reduce the price of subscribing to the internet.

Funding: This research received no external funding.

Acknowledgments: The author thanks the anonymous reviewers and the editor for their useful comments.

Conflicts of Interest: The author declares no conflict of interest. 


\section{References}

Abu, T. \& Bressler, L. (2019). Energy security in Israel and Jordan: The role of renewable energy sources. Renewable Energy, 135, 378-389.

Arellano, M. \& Bond, S. (1991). Some tests of specification for panel data: Monte Carlo evidence and an application to employment equations. Rev. Economic Studies, 58 (2), 277-297.

Arellano, M. \& Bover, O. (1995). Another look at the instrumental variable estimation of error components models. Journal of Econometrics 68 (1), 29-51.

Asongu, S. A., Le, S. \& Biekpe, N. (2017a). Enhancing ICT for environmental sustainability in sub-Saharan Africa. Technological Forecasting \& Social Change, 1-8.

Asongu, S. A., Le, S.\& Biekpe, N. (2017b). Environmental degradation, ICT, and inclusive development in SubSaharan Africa. Energy Policy, 111, 353-361

Asongu, S. A., \& Acha-Anyi, P. N., (2019). The Murder Epidemic: A Global Comparative Study. International Criminal Justice Review, 29(2), 105-120.

Asongu, S. A., \& Odhiambo, N. M., (2019). Insurance Policy Thresholds for Economic Growth in Africa. The European Journal of Development; DOI: /10.1057/s41287-019-00234-2.

Boateng, A., Asongu, S. A., Akamavi, R., \& Tchamyou, V. S., (2018). Information Asymmetry and Market Power in the African Banking Industry. Journal of Multinational Financial Management, 44(March), 69-83.

Benighaus, C. (2019). Neither risky technology nor renewable electricity: Contested frames in the development of geothermal energy in Germany. Energy Research \& Social Science, 47(August 2018), 46-55.

Baltagi, B. H. (2008). Forecasting with panel data. Journal of Forecast 27 (2), 153-173.

Bhattacharya, M., Awaworyi Churchill, S. \&Paramati, S. R. (2017). The dynamic impact of renewable energy and institutions on economic output and $\mathrm{CO}_{2}$ emissions across regions. Renewable Energy, 111, 157-167.

Blundell, R. \& Bond, S. (1998). Initial conditions and moment restrictions in dynamic panel data models. Journal of Econometrics 87 (1), 115-143.

Céspedes-lorente, J. J., \& Magán-díaz, A. (2018). Information technologies and downsizing: Examining their impact on economic performance. Information $\mathcal{E}$ Management, (April 2016), https://doi.org/10.1016/j.im.2018.09.012.

Donou-adonsou, F. (2018). Technology, education, and economic growth in Sub-Saharan Africa. Telecommunications Policy, (August), http://doi.org/10.1016/j.telpol.2018.08.005

Erumban, A. A. \& Kusum, D. (2016). Information and communication technology and economic growth in India. Telecommunications Policy, 40(5), 412-431.

Hache, E. (2018). Do renewable energies improve energy security in the long run? International Economics, 156 ,127-135.

Haftu, G. G. (2018). Information communications technology and economic growth in Sub-Saharan Africa: A panel data approach. Telecommunications Policy, 1-13.

IEA (2017). International Energy Agency.

Jorgenson, D. W., Ho, M. S. \& Samuels, J. D. (2016). The impact of information technology on postwar US economic growth. Telecommunications Policy, 40(5), 398-411.

Lin, B. \& Chen, Y. (2019). Does electricity price matter for innovation in renewable energy technologies in China? Energy Economics, 78, 259-266.

Mehdi, B. J. \& Slim, B. Y. (2017). The role of renewable energy and agriculture in reducing $\mathrm{CO}_{2}$ emissions: Evidence for North Africa countries. Ecological Indicators, 74, 295-301.

Pfeifer, A., Dobravec, V., Pavlinek, L.\&Kraja, G. (2018). Integration of renewable energy and demand response technologies in interconnected energy systems. Energy. 161, 447-455.

Pradhan, R. P., Arvin, M. B. \& Norman, N. R. (2015). The dynamics of information and communications technologies infrastructure, economic growth, and financial development: Evidence from Asian countries. Technology in Society, 42, 135-149.

Pradhan, R. P., Mallik, G. \& Bagchi, T. P. (2018). Information communication technology (ICT) infrastructure and economic growth: A causality evinced by cross-country panel data. IIMB Management Review, 30(1), 91-103.

Ribeiro, F., Ferreira, P., Araújo, M. \& Braga, A. C. (2018). Modeling perception and attitudes towards renewable energy technologies. Renewable Energy, 122, 688-697.

Roodman, D. (2009). How to do xtabond2: An introduction to difference and system GMM in Stata. Stata Journal, $9(1), 86-136$ 
Salahuddin, M. \& Alam, K. (2016). Information and communication technology, electricity consumption, and economic growth in OECD countries: A panel data analysis. Electrical Power and Energy Systems, 76, 185-193.

Tchamyou, V.S., Erreygers, G., \& Cassimon, D., (2019). Inequality, ICT, and Financial Access in Africa, Technological Forecasting and Social Change,139, 169- 184.

Thompson, M. (2018). Social capital, innovation, and economic growth. Journal of Behavioral and Experimental Economics, 73, 46-52.

World Bank. (2016). World Development Indicators. Available at http://www.worldbank.org/

World Bank. (2016). African Development Indicators. Available at http://www.worldbank.org/

Yang, Y., Ren, J., Stubbe, H., Xu, D. \& Tien, T. (2018). Using multi-criteria analysis to prioritize renewable energy home heating technologies, 29, 36-43.

(C) 2020 by the authors. This article is an open-access article distributed under the terms and conditions of the Creative Commons Attribution (CC BY) license (http://creativecommons.org/licenses/by/4.0/). 